\title{
Development of a Selective Mixed-Potential Ammonia Sensor for Automotive Exhausts
}

\author{
Gita Nematbakhsh Abkenar ${ }^{1 *}$, Jean-Paul Viricelle ${ }^{1}$, Mathilde Rieu $^{1}$ and Philippe Breuil ${ }^{1}$ \\ ${ }^{1}$ Mines Saint-Etienne, Univ Lyon, CNRS, UMR 5307 LGF, Centre SPIN, F - 42023 Saint-Etienne France \\ *Tel : +33477420252, E-mail : viricelle@emse.fr
}

\begin{abstract}
One of the most effective technologies in decreasing large-scale $\mathrm{NO}_{\mathrm{x}}$ emission produced by diesel engine vehicles is Urea-SCR (selective catalytic reduction) system. In order to prevent inducing excessive ammonia to the environment, an $\mathrm{NH}_{3}$ sensor is required at the exit of this system [1, 2]. In this study, highly selective ammonia sensors were developed to detect ammonia emissions from automotive exhaust.

The sensors were fabricated with 8-YSZ electrolyte, a platinum reference electrode and a working electrode of $\mathrm{Au}-\mathrm{V}_{2} \mathrm{O}_{5}$ (mass ratio 85/15), screen-printed on an alumina substrate. A platinum resistor was printed at the backside of the support to control the sensor temperature. The measured sensor' response $(\Delta \mathrm{V})$ is the potential difference between reference and working electrodes. Figure 1 shows the responses of two identical sensors to $100 \mathrm{ppm} \mathrm{CO}, \mathrm{NO}_{2}, \mathrm{NO}$ and $20 \mathrm{ppm}$ of $\mathrm{NH}_{3}$ at four different temperatures. It can be seen that the sensors respond to all gases at lower temperatures while by increasing temperature to $600^{\circ} \mathrm{C}$, the selectivity to $\mathrm{NH}_{3}$ is greatly improved. The selectivity of sensors was also confirmed by testing other possible interfering gases: no responses were observed for $20 \mathrm{ppm}$ of hydrogen and $100 \mathrm{ppm}$ of a hydrocarbon mixture.

The stability of such sensors was studied at $550^{\circ} \mathrm{C}$ and $600^{\circ} \mathrm{C}$. Since the sensors show no long-term stability at $600^{\circ} \mathrm{C}$ (electrode degradation), but remain stable at $550{ }^{\circ} \mathrm{C}$, investigations were made to decrease the working temperature while maintaining selectivity. After testing different mass percentages of $\mathrm{V}_{2} \mathrm{O}_{5}$ in working electrode, we observed that by increasing this value to $50 \%$, the working temperature of selective ammonia sensors could be decreased to $550^{\circ} \mathrm{C}$ with stable responses.

Further investigations will be performed in order to gain deeper insight in sensing mechanism of $\mathrm{V}_{2} \mathrm{O}_{5}$ based working electrodes, which governs the sensor's performance.
\end{abstract}

\section{References}

[1] K. Shimizu, I. Chinzei, et al. "Doped-vanadium oxides as sensing materials for high temperature operative selective ammonia gas sensors," Sensors and Actuators B, 141, 2009, pp. 410-416.

[2] M. Van Nieuwstadt, I. Dpadhyay, et al. "Control of Urea SCR Systems for US Diesel Applications" in IFP Energies Nouvelles International Conference, Dearborn, USA, 2011, pp. 655-665. 


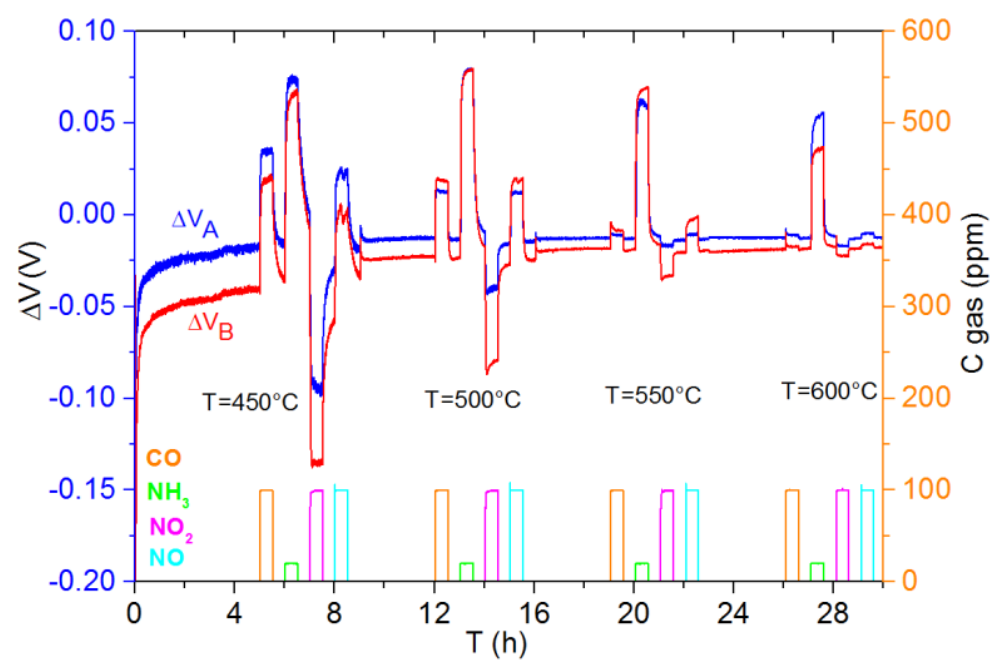

Figure 1 : Responses of $\mathrm{Au}-15 \% \mathrm{~V}_{2} \mathrm{O}_{5}$ electrode $\mathrm{YSZ}$ based sensors to $\mathrm{CO}, \mathrm{NH}_{3}, \mathrm{NO}_{2}$ and $\mathrm{NO}$ at temperatures of $450,500,550$ and $600^{\circ} \mathrm{C}$. 